\title{
California enacts law to strengthen conservation bank program
}

C

alifornia's landmark conservation banking program, launched by executive order in 1995, was the first of its kind nationwide — but until now was never part of statutory law.

Now this 18-yearold program is backed by new legislation (SB 1148), effective in January.

Although a bellwether program that led to establishment of 29 banks, the executive order lacked clear regulatory standards or procedures, says David Bunn, researcher for the Wildlife Health Center at UC Davis.

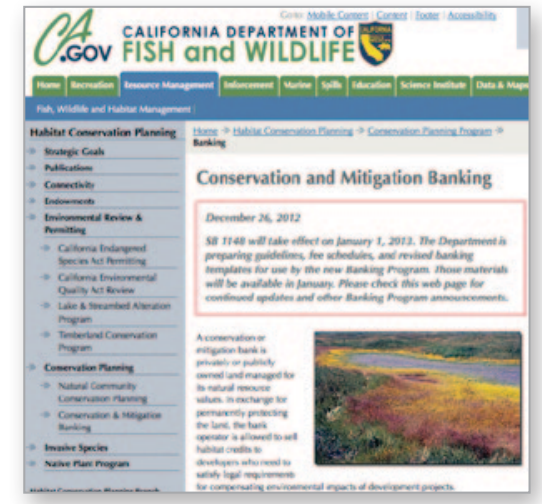

For more information: http://www.dfg. ca.gov/habcon/conplan/mitbank/ caused negotiations over potential new banks to drag on for 5 or more years," he added.

New bank approvals have dropped in recent years; most of the state's conservation banks were approved before 2006, and none have been approved since 2009.

"The economic recession also contributed to the dwindling use of the program," said Bunn. "These banks achieve conservation goals by providing credits to developers who need to mitigate environmental impacts of development. There was Bunn authors an article in this issue (page much less demand for credits after the 86) reporting findings from the first assessment of the program.

"The lack of statutory standards reduced the program's usefulness and dropoff in construction statewide - so less market incentive to establish them."

Now Senate Bill 1148 has created a clear regulatory framework for the program that could become a model for other states, according to Bunn.

Bunn's study finds that three key actions are needed to address the many difficult challenges of conservation banking in the state: 1) enacting standards in statutes for critical program components such as prioritizing potential bank sites, 2) adding experienced program-dedicated staff to implement the program and 3) establishing a regional approach to planning and monitoring.

"The passage of SB 1148 is a good first step to addressing some of the major program challenges identified in our research, and the new authorizations for fees make it possible to fund additional dedicated staff for the program," said Bunn, lead investigator of the research. "The bill adds clarity to application procedures. However, further legislation is needed to establish standards for prioritizing potential conservation bank sites within a region."

- Janet White

\section{Letters}

\section{Issues in contemporary agriculture}

In Albany, in the aftermath of the illegal occupation of the Gill Tract, members of the Albany City Council have been in discussion with Dean Keith Gilless of the UC Berkeley College of Natural Resources on the future of the Gill Tract and the sort of community programs that could be available there.

California Agriculture journal, especially the January-March 2013 issue, provides the council with an excellent overview of contemporary issues in agriculture and of the variety of educational, environmental and nutritional programs sponsored by ANR.

\section{Michael Barnes}

Albany City Council Member

\section{Correction: Location of Pigeon Point lighthouse}

Great job on the January-March 2013 California Agriculture issue! We are interested in UC agricultural and natural resources research because our company specializes in alternative urban farming and gardening, and the Food and Solar Energy Co-Production Project.

On page 62, "Nitrogen fertilizer use in California: Assessing the data, trends and a way forward," the picture of Pigeon Point Lighthouse with cole crop plants in the foreground was identified as located in Santa Cruz County. Pigeon Point Lighthouse is in San Mateo County.

Greg Scott

Emergence Farms and Gardens

Newark/Fremont, CA (South Alameda County)

Editor's note: Thank you for the correction; we entered it in the E-Edition, and the print version in this issue. California Agriculture regrets the error.

\section{Production and access to nutritious food}

Thank you for the coverage in the January-March 2013 edition. At UCCE Marin, we are providing steering committee leadership for the Marin Food Policy Council. This is a broad stakeholder body focusing on the development and implementation of policy to increase production of, and access to, healthy nutritious food.

Everything in the issue is relevant to our current and upcoming discussions.

David J. Lewis, Director

University of California Cooperative Extension

Marin County
RSVP

\section{WHAT DO YOU THINK?}

The editorial staff of California Agriculture welcomes your letters, comments and suggestions. Please write to us at: 1301 S. 46th St., Building 478 - MC 3580 , Richmond, CA 94804, orcalag@ucanr.edu. Include your full name and address. Letters may be edited for space and clarity.

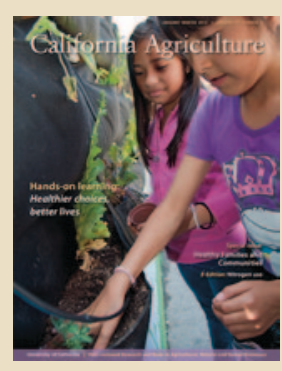

January-March 2013 California Agriculture 